\title{
O LEGADO DE CELSO DANIEL PARA A GESTÃO PÚBLICA
}

\author{
Marta Ferreira Santos Farah \\ Professora do Departamento de Fundamentos \\ Sociais e Jurídicos da Administração da \\ FGV-EAESP e Vice-Coordenadora do \\ Programa Gestão Pública e Cidadania. \\ E-mail: mfarah@fgvsp.br
}

\section{INTRODUÇÃO}

A gestão pública local no Brasil acaba de perder um de seus representantes mais criativos e dinâmicos: Celso Daniel, morto de forma trágica no início deste ano. Embora ainda jovem, ele deixou um legado de idéias e práticas que devem ser examinadas com cuidado por todos aqueles comprometidos com o aperfeiçoamento da adminis- globalização, pela reestruturação produtiva, pelo desemprego e pela superação do modelo do Estado Nacional-Desenvolvimentista.

Sua reflexão sobre tais processos e desafios foi fortemente influenciada pelo impacto dessas alterações sobre a cidade em que morava - Santo André - e sobre a região em que esta se situa - o Grande $\mathrm{ABC}$, na região metropolitana de São Paulo. Essa região, caracteri-

\section{Para Celso, a administração pública deVe incluir a política. Política enquanto EXERCÍCIO DO DIÁLOGO E DA NEGOCIAÇÃO,}

\section{EM BUSCA DO INTERESSE COLETIVO.}

tração pública e do governo no país.

A atuação de Celso, como administrador e como político, nasceu de uma reflexão crítica sobre mudanças recentes na sociedade e no Estado contemporâneos e de sua preocupação com os desafios que se apresentam ao Estado e à sociedade brasileira num quadro marcado pela zada por grande dinamismo do setor industrial desde os anos 50, tendo como eixo a indústria automobilística, sofreu intensamente os impactos da globalização e da reestruturação produtiva a partir do final da década de 80: desde então, assiste-se, no Grande ABC, à decadência das atividades econômicas "tradicionais" da região, num processo marcado pelo êxodo de indústrias, pela obsolescência do parque industrial local e pelo crescimento do desemprego, que chegou a atingir, na segunda metade dos anos 90 , a taxa de $20 \%$, superior à da região metropolitana de São Paulo.

A busca de alternativas para Santo André e para a região do $\mathrm{ABC}$ consistiu num dos principais eixos articuladores da ação de Celso, sendo um dos estímulos principais de algumas de suas mais criativas proposições e realizações, baseadas na idéia da viabilidade do desenvolvimento local e regional.

Sua ação política e administrativa foi também influenciada por sua preocupação em relação a questões urbanas de implicações regionais, tais como a habitação de interesse social, a destinação de resíduos sólidos - do lixo urbano - e a preservação de recursos hídricos. Mais uma vez, a realidade de Santo André e de sua região constituiu um importante elemento desencadeador dessa reflexão: $56 \%$ da superfície da região do Grande $\mathrm{ABC}$ encontra-se em área de proteção de 
mananciais, ocupada em grande parte por loteamentos irregulares. A busca de soluções duradouras para esses desafios foi um estímulo importante para a atuação de Celso como prefeito.

\section{POLÍTICA E ADMINISTRAÇÃO:} A ARTICULAÇÃO NECESSÁRIA

Ao mencionar algumas das questões que influenciaram a atuação de Celso, vale destacar um aspecto que sobressai em sua prática como administrador e como político: a subordinação da ação governativa e da prática administrativa a objetivos de caráter coletivo, decorrentes da clara identificação de problemas a serem enfrentados. Embora essa subordinação possa parecer evidente, não é difícil reconhecer que ela não constitui uma característica dominante da administração pública no Brasil.

A análise de suas realizações como administrador e como político também expõe sua convicção de que política e administração não são pólos antagônicos. Celso contrapõe-se, portanto, à tendência que atribui à administração um caráter exclusivamente racional e técnico, necessariamente dissociado da política. A política seria, nessa perspectiva, responsável pela ineficiência, decorrente de práticas clientelistas e patrimonialistas.

Para Celso Daniel, a administração pública deve incluir a política. Política enquanto exercício do diálogo e da negociação, em busca do interesse coletivo. Ao enfatizar a importância da negociação, Celso reconhece que a administração pública se efetiva em um contexto que envolve freqüentemente conflitos entre interesses distintos, entendendo que apenas o reconhecimento desses conflitos viabiliza a construção de consensos em torno de alguns objetivos comuns.

A administração pública também deve incluir a política, no sentido de uma prévia definição de princípios e compromissos, que devem servir como parâmetros norteadores da administração pública. Para Celso, a política consiste em compromisso com a ética, com o desenvolvimento e com a justiça social.

\section{ÉTICA, DESENVOLVIMENTO LOCAL E CIDADANIA}

O compromisso com a ética na gestão pública constituía, para Celso, um dos ingredientes centrais da mudança necessária da relação entre Estado e sociedade no Brasil. Uma mudança que rompa com o favoritismo, com o clientelismo, da influência de processos de âmbito nacional e internacional sobre o espaço local, ele defendia, no entanto, o desenvolvimento local e regional como estratégia capaz de enfrentar de forma eficaz os desafios oriundos da globalização e da reestruturação produtiva.

A prioridade atribuída ao desenvolvimento local é acompanhada, no pensamento de Celso Daniel, pela opção por um modelo de desenvolvimento no qual a redução da desigualdade ocupe um lugar central. Assim, embora comprometido com a recuperação do nível de atividade econômica no Grande ABC, a estratégia de desenvolvimento local e regional proposta por ele não

\section{A PRIORIDADE ATRIBUÍDA AO DESENVOLVIMENTO}

\section{LOCAL É ACOMPANHADA PELA OPÇÃO POR UM MODELO DE DESENVOLVIMENTO NO QUAL A REDUÇÃO}

\section{DA DESIGUALDADE OCUPE UM LUGAR CENTRAL.}

com o atendimento de demandas com base em critérios pessoais ou no acesso privilegiado de alguns grupos ao espaço de decisão, por força do poder econômico ou do poder político. Ele estava convencido de que a instituição de um padrão ético de relação entre Estado e sociedade no Brasil supunha a ruptura da lógica do tipo "Você sabe com quem está falando?”, tão bem analisada por Roberto DaMatta, e sua substituição por uma cidadania do tipo impessoal, em que todos os cidadãos sejam de fato "iguais perante a lei" e perante as agências estatais.

O compromisso com o desenvolvimento, por sua vez, ocupou lugar central nas três gestões de Celso como prefeito de Santo André, sendo também um eixo articulador de sua produção acadêmica. Sem desconsiderar a importância de um projeto de desenvolvimento nacional e tampouco desconhecer a relevância envolvia um esforço de atração de empresas "a qualquer preço". Pelo contrário, sua estratégia orientavase para a garantia da retomada do desenvolvimento regional, ao mesmo tempo em que procurava aumentar o nível de emprego e a qualidade de vida em Santo André e na região. Segundo o próprio Celso (Uma estratégia econômica para o grande ABC, São Paulo em Perspectiva, v. 10, n. 3, jul./set. 1996, p. 142): “(...) tal estratégia persegue o fortalecimento dos fornecedores locais da grande empresa (em sintonia com uma política industrial voltada à preservação do complexo industrial); a participação ativa dos sindicatos em processos de negociação de salários, emprego, jornada de trabalho, modernização tecnológica e democratização de trabalho; a melhoria da qualidade de vida; o combate a deseconomias de aglomeração (congestionamentos, enchentes); e ações ligadas à busca 
de benefícios regionais (educação para o trabalho, apoio à pequena empresa e ao setor informal), pressupondo capacidade de investimento público e, portanto, os correspondentes recursos tributários."

A preocupação com a cidadania e com a redução da desigualdade foi uma constante na trajetória de Celso. Segundo ele, a formulação de planos de governo e a definição de práticas e estruturas administrativas deveriam subordinar-se, portanto: a) à ampliação do espaço público, de forma a permitir a participação ativa dos cidadãos nas definições das políticas públicas; b) à garantia universal de acesso a oportunidades de trabalho e a serviços públicos e c) ao esforço de combate à pobreza e à redução da desigualdade. Sua preocupação com a exten- líticos e das instituições governamentais. Isso significa uma administração pública capaz de fazer um uso responsável e transparente de recursos públicos, baseando-se em critérios impessoais no atendimento a demandas e na relação com fornecedores do setor privado, de forma a romper com o favoritismo, com o clientelismo e com a corrupção. A modernização da administração, nesse sentido, estaria a serviço da ética, um dos compromissos "políticos" que, segundo Celso, deveria nortear a administração pública.

A modernização da administração pública deveria, em segundo lugar, buscar a agilidade e eficiência da máquina estatal, de forma a garantir um bom atendimento ao cidadão. Essa dimensão da modernização envolvia, de um lado, a ca-

\section{A MODERNIZAÇÃO DA ADMINISTRAÇÃO ESTARIA}

\section{A SERVIÇO DA ÉTICA, UM DOS COMPROMISSOS "políticos" que, Segundo Celso, deVeria NORTEAR A ADMINISTRAÇÃO PÚBLICA.}

são da cidadania traduziu-se não apenas no esforço de universalização do acesso aos diversos serviços públicos - como educação, saúde, lazer e infra-estrutura urbana - mas também na incorporação, no âmbito de ação governamental, de "novos" segmentos da população, tais como as mulheres, atingidas fortemente pelo processo de pauperização, e crianças e adolescentes em situação de risco social.

\section{MODERNIZANDO A} ADMINISTRAÇÃO PÚBLICA

Celso defendia ainda a "modernização" da administração pública no Brasil. Essa modernização deveria, em primeiro lugar, contribuir para romper com vícios históricos que levaram ao descrédito dos po- pacitação do funcionalismo e sua valorização e, de outro, a simplificação de procedimentos e o investimento na garantia de acesso dos cidadãos a informações sobre os serviços prestados pelo governo. A tecnologia da informação deveria estar a serviço desses objetivos.

Outro traço marcante de Celso era sua preocupação permanente em não ser "tragado" pela ação, deixando de lado a capacidade de reflexão e crítica. Assim, paralelamente à sua atividade como administrador e político, ele continuava "mergulhado" no ambiente universitário, inicialmente como aluno - cursando pós-graduação - e, desde o final dos anos 80, como professor: de administração pública na FGVEAESP e de economia na PUC-SP. A outra face dessa sua concepção sobre a necessidade de articulação entre o "fazer" e o "pensar" era sua defesa de uma educação superior conectada com a realidade, produzindo conhecimento relevante aos desafios enfrentados pela sociedade.

Tais orientações marcaram sua atuação com prefeito de Santo André, durante três gestões. A análise das políticas e programas desenvolvidos durante essas gestões permite considerar Celso Daniel como um dos mais importantes representantes de uma nova gestão pública local no Brasil.

\section{UMA NOVA GESTÃO LOCAL}

Essa nova gestão local surgiu com o início do processo de democratização, mas tem como marco institucional a Constituição de 1988, que assinala o início de um ciclo descentralizador no federalismo brasileiro. A partir da nova constituição, houve uma redefinição do papel dos municípios no país. Estes receberam, de um lado, uma parcela mais expressiva de recursos fiscais, por determinação constitucional. De outro, em que pesem as ambigüidades que ainda hoje persistem em relação a competências nas mais diversas áreas, houve uma efetiva transferência de atribuições para o nível local de governo. Os municípios passaram, assim, a assumir a responsabilidade pela formulação e implementação de diversas políticas públicas, sobretudo na área social. Ao mesmo tempo, a própria crise do Estado central levou a um relativo "abandono" das esferas locais, que tiveram que buscar estratégias para lidar com o impacto da globalização, da abertura do mercado e da reestruturação produtiva sobre seus territórios.

Esse contexto definiu novos e crescentes desafios para a gestão local. Nesse novo cenário, surgiram ações inovadoras de governos locais que procuram responder às novas demandas enfrentadas pelos 
municípios. Essa nova gestão pública local - promovida por prefeitos de diversos partidos - veio romper com as práticas excludentes e clientelistas que marcaram a gestão pública no Brasil até recentemente.

\section{A PRÁTICA INOVADORA}

Nas gestões de Celso em Santo André, há um repertório de experiências inovadoras em gestão local que merece a atenção de administradores, políticos e de alunos de administração, tanto pelos princípios que as norteiam quanto pelos processos em que se baseiam.

Destacam-se quatro exemplos: o Programa de Modernização Administrativa de Santo André, o Programa Integrado de Inclusão Social, o projeto Grafitti Nossa pArte e a Câmara do Grande ABC.

O Programa de Modernização Administrativa de Santo André procurou modificar estruturas e procedimentos da administração municipal, tornando-a mais ágil e eficiente, de forma a facilitar o acesso dos cidadãos a informações e a serviços oferecidos pela prefeitura. Esse programa inclui: a) implantação de postos de atendimento reunindo diversos serviços públicos em um único local, contando também com sistemas informatizados; b) disponibilização de informações no site da prefeitura e prestação de serviços por meio da Internet; c) implantação de um serviço que possibilita o acesso a informações e a solicitação de documentos por telefone; d) formação e capacitação do funcionalismo.

O Programa Integrado de Inclusão Social, por sua vez, tem como alvo segmentos da população municipal excluídos do acesso ao emprego e a serviços públicos. Tendo em vista a concentração desses segmentos em áreas urbanas degradadas, particularmente em favelas, esse programa dirige suas ações para essas áreas. Partindo do entendimento de que a exclusão social é um fenômeno multidimensional, causado por fatores econômicos, sociais, políticos e culturais, tal programa adota como estratégia a implantação simultânea e coordenada de projetos de diversos setores habitação, saúde, educação, lazer, acesso a crédito e formação profissional - em um mesmo território, visando ao mesmo tempo o estabelecimento de uma rede de proteção social e a emancipação das famílias atendidas, por meio de programas de geração de emprego e renda. jovens. Celso era grande entusiasta dessa iniciativa pioneira, em que jovens grafiteiros recebem apoio institucional da prefeitura, participando de experiências de criação coletiva que, ao mesmo tempo, contribuem para o embelezamento e recuperação de espaços urbanos deteriorados. Por meio dessa experiência, jovens - até então, sem espaço de expressão e de inserção social - participam como cidadãos da própria "construção da cidade", o que, sem dúvida, constitui também uma estratégia de combate à violência urbana.

\section{A outra face da concepÇÃo de Celso}

\section{SOBRE A NECESSIDADE DE ARTICULAÇÃO ENTRE O "FAZER" E O "PENSAR" ERA SUA DEFESA DE UMA EDUCAÇÃO} SUPERIOR CONECTADA COM A REALIDADE.

Para contrapor-se à situação de exclusão - associada a péssimas condições de vida, à desestruturação familiar e à intensificação da violência, principalmente entre os jovens -, desenvolve-se uma abordagem que permite a recuperação da auto-estima e a efetiva inserção social da população atendida. Constituem alguns exemplos de projetos e subprogramas desenvolvidos no âmbito do Programa Integrado de Inclusão Social: o Programa de Garantia de Renda Familiar Mínima, a Incubadora de Cooperativas, o Programa de Coletores Comunitários, o Programa Gênero e Cidadania, o Saúde da Família, o Criança Cidadã, dentre outros.

Nessa mesma perspectiva de inclusão, o projeto Grafitti Nossa pArte tem como foco um segmento particularmente atingido pela ausência de perspectivas de inserção social e ainda hoje negligenciado pelas políticas públicas: os
Uma característica central de vários programas desenvolvidos durante as gestões de Celso consiste nessa participação direta da população no desenvolvimento da ação governamental. No Programa de Inclusão Social, por exemplo, definidas as estratégias gerais de atuação, a implantação efetiva das ações em cada local é precedida de discussões com a população, o que influencia o desenho do programa em cada favela, refletindo o leque de prioridades de cada comunidade.

A importância da inclusão de outros participantes na formulação e implementação de políticas e programas consiste em uma das principais teses defendidas por Celso: a participação como forma de democratizar a ação estatal e seus resultados - as políticas públicas. Para ele, essa participação é hoje algo essencial ao governo local, indo além da participação da comunidade beneficiária. É crucial também o envolvimento de outros seg- 
mentos da sociedade, como o setor empresarial, os sindicatos, as associações comunitárias, etc.

\section{NOVOS ARRANJOS \\ INSTITUCIONAIS: CONSTRUINDO CONSENSOS}

O quarto dos programas mencionados - a Câmara do Grande ABC - baseia-se nessa participação ampliada. Esse programa evidencia a ênfase à cooperação e à construção de consensos na atuação de Celso como administrador público. A Câmara é um fórum intergovernamental de planejamento, formulação e implementação de políticas públicas, que reúne sete prefeituras do $\mathrm{ABC}$, com foco no desenvolvimento sustentável da região, afetada pela
Como visto, a gestão de recursos hídricos constituía, desde então, uma prioridade para a região, boa parte situada em área de proteção de mananciais e ameaçada pela ocupação predatória dessas áreas, com prejuízo para a qualidade da água. A partir desse primeiro foco de cooperação, o Consórcio passou a incluir também a preocupação com o desenvolvimento da região, afetada pelo desemprego e pela desindustrialização.

Tendo também como antecedentes a Câmara Setorial Automobilística de 1992-1993 - composta por sindicatos, empresários e poder público - e o Fórum da Cidadania do ABC, criado em 1994 e constituído por representantes de movimentos e entidades da região, a Câmara do Grande ABC constitui

\section{O projeto Grafitti Nossa pArte tem}

\section{COMO FOCO UM SEGMENTO PARTICULARMENTE}

\section{ATINGIDO PELA AUSÊNCIA DE PERSPECTIVAS}

\section{DE INSERÇÃO SOCIAL: OS JOVENS.}

crise de suas atividades econômicas tradicionais e pelo crescimento do desemprego. A Câmara, da qual ele foi um dos idealizadores e a principal liderança, caracteriza-se pela cooperação entre governo e sociedade civil, reunindo prefeitos, poder legislativo, governo do Estado e representantes de empresários, de trabalhadores e de outros segmentos da sociedade civil.

A Câmara constitui um desdobramento de iniciativa anterior, o Consórcio Intermunicipal das Bacias Billings e Tamanduatehy, criado em dezembro de 1990 por sete prefeituras do ABC, sob a liderança da prefeitura de Santo André, tendo por objetivo inicial a formulação e implantação conjunta de um modelo de gestão de recursos hídricos para a região, com foco na destinação de resíduos sólidos. um arranjo institucional inovador caracterizado pela articulação entre Estado e sociedade civil e pela colaboração intergovernamental.

Em 1996, antes, portanto, da criação da Câmara, mas já prenunciando a constituição desse arranjo institucional inovador, Celso escreveu (Uma estratégia econômica para o grande ABC, São Paulo em Perspectiva, v. 10, n. 3, jul./set. 1996, p. 138) "A constituição de uma vontade coletiva regional, partindo do que já se acumulou, significa um salto de qualidade indispensável para o enfrentamento do desafios postos pela economia regional, expresso na criação de um arranjo institucional de novo tipo, fruto de uma coalização ampla que integre, num mesmo espaço público não puramente estatal, os poderes públicos e a sociedade civil locais."
A liderança exercida por Celso nesse Fórum regional não só mostra uma concepção de desenvolvimento local e regional bastante inovadora. Ela evidencia, sobretudo, sua concepção de que a gestão pública hoje passa, necessariamente, pela construção de consensos sobre prioridades de ação, sobre fontes de recursos e, principalmente, sobre as medidas a serem adotadas para viabilizar tais prioridades.

Uma das lições que Celso nos deixa é exatamente esta: diante dos desafios extremamente complexos com que o Estado e a sociedade brasileira se defrontam hoje, é preciso que governantes e administradores públicos sejam capazes de liderar processos de negociação entre interesses diversos. A problemática de Santo André e do Grande ABC constitui um exemplo paradigmático. O reconhecimento por empresários, trabalhadores e outros segmentos da comunidade local e regional de que havia problemas comuns que atingiam a todos - poluição dos mananciais, desindustrialização, fuga de capitais e desemprego - possibilitou o início de um processo de diálogo na busca da formulação de saídas conjuntas que beneficiassem a todos.

Essa lição pode inspirar também a busca de soluções para a violência que atinge toda a sociedade brasileira - sendo a responsável pela prematura morte de Celso - e que hoje chega a ameaçar o próprio Estado. A solução - que deve ser buscada com urgência - deverá vir, antes de mais nada, de uma abordagem integral das causas da violência, do que decorrerá uma ação também necessariamente integral e multidimensional. Essa ação, por sua vez, precisará contar com a cooperação entre Estado e sociedade civil, assim como com a colaboração intergovernamental. Tal cooperação só poderá se efetivar se houver o reconhecimento de que a violência é um problema que hoje atinge a todos e que, portanto, é um problema de todos nós. $\bigcirc$ 